\title{
Subchronic Oral Toxicity Study of Acanthopanax divaricatus var. albeofructus in Rats
}

\author{
Myoung Jun Kim ${ }^{1}$, Mi Ju Lee ${ }^{2}$, Yong-Hoon Lee ${ }^{2}$, Sun Hee Park', Duyeol Kim', \\ Cheol Beom Park ${ }^{1}$, Jin Seok Kang ${ }^{3}$ and Jong-Koo Kang ${ }^{4}$ \\ ${ }^{1}$ Department of Pathology, Biotoxtech Co., Ltd., Cheongju, Korea \\ ${ }^{2}$ Department of Pathology, Chronic Inhalation Toxicity Research Center, Chemicals Toxicity Research Bureau, \\ Occupational Safety and Health Research Institute, Korea Occupational Safety and Health Agency, Daejeon, Korea \\ ${ }^{3}$ Department of Biomedical Laboratory Science, Namseoul University, Cheonan, Korea \\ ${ }^{4}$ Department of Laboratory Animal Medicine, College of Veterinary Medicine, Chungbuk National University, Cheongju, Korea
}

(Received June 30, 2016; Revised December 8, 2016; Accepted December 9, 2016)

\begin{abstract}
Acanthopanax divaricatus (Siebold \& Zucc.) Seem. var. albeofructus (ADA), a traditional medical herb, has been used to treat arthritis and muscular injury, to strengthen muscle and bone, and to get vital energy. However, information regarding its toxicity is limited. ADA was administered by oral gavage to groups of rats at doses of 0 (control), 1,000, 1,500, 2,000, 2,500, and 3,000 mg/kg five times per week for 13 weeks. Mortality, clinical signs, body weights, food consumption, hematology, serum chemistry, urinalysis, organ weights, necropsy, histopathological finding, vaginal cytology, and sperm morphology were compared between control and ADA-treated groups. Salivation was intermittently observed in both sexes receiving 2,500 and $3,000 \mathrm{mg} / \mathrm{kg}$ directly after dosing. Absolute liver weights increased in females receiving 2,000, 2,500 , and $3,000 \mathrm{mg} / \mathrm{kg} \mathrm{ADA}(P<0.05, P<0.01$, and $P<0.01$, respectively) and so did the relative liver weights $(P<0.001)$. Salivation and increased liver weight were ADA-related changes but not considered to be adverse effects. Salivation was intermittent and transient, and the liver weight increase was minor and not accompanied by other changes such as hepatic morphological or functional alterations. The noobserved-adverse-effect-level was determined to be at least $3,000 \mathrm{mg} / \mathrm{kg}$ in both sexes of rats.
\end{abstract}

Key words: Acanthopanax divaricatus (Siebold \& Zucc.) Seem. var. albeofructus, Subchronic toxicity, Rats, NOAEL

\section{INTRODUCTION}

Acanthopanax species are commonly used in Asia as medical herbs and are widely distributed across Asia. The genus Acanthopanax of the Araliaceae family includes approximately 20 species of shrubs. Traditionally, the cor-

Correspondence to: Jin Seok Kang, Department of Biomedical Laboratory Science, Namseoul University, 91, Daehak-ro, Maeju-ri, Seobuk-gu, Cheonan-si, Chungcheongnam-do 31020, Korea

E-mail: kang@nsu.ac.kr

Jong-Koo Kang, Department of Laboratory Animal Medicine, College of Veterinary Medicine, Chungbuk National University, 1, Chungdae-ro, Seowon-gu, Cheongju-si, Chungcheongbuk-do 28644, Korea

E-mail: jkkang@cbu.ac.kr

This is an Open-Access article distributed under the terms of the Creative Commons Attribution Non-Commercial License (http:// creativecommons.org/licenses/by-nc/3.0) which permits unrestricted non-commercial use, distribution, and reproduction in any medium, provided the original work is properly cited. tex of the root and stem of Acanthopanax species has been used to treat rheumatoid arthritis, tetraplegia, fracture, contusion, edema, and hypertension, and to strengthen muscle and bone (1-3). It also has been considered to be good for vital energy and used for sleeplessness with many dreams, lower back or kidney pain, deficiency of yang in the kidney and spleen, lack of appetite, and to enhance the overall resistance to disease, adverse physical influences, or stress (4).

Extensive biological studies on Acanthopanax divaricatus (Siebold \& Zucc.) Seem. var. albeofructus (ADA) have been conducted to date, revealing its pharmacological activities. For example, ADA exerts anti-inflammatory effects by suppressing the expression of genes encoding inflammatory proteins through inhibition of nuclear factor-B and activator protein-1-binding activities (5), neuroprotective effects (6), behavioral alterations in murine sleep deprivation (7), and diminution of physical fatigue and improvement of physical strength in chronic swimming-stressed rats (8).

Acanthoside D and chiisanoside are well known as the 
principal active components of ADA (2,3,9-12). It has been reported to reduce the behavioral alterations induced by sleep deprivation (7), to show anti-inflammatory effects (5), and to reduce the degree of ischemia-reperfusion injury in the rat liver (13). Chiisanoside has also been reported to have anti-inflammatory effects, including in rheumatoid arthritis (14), in addition to antibacterial activity (15), anticancer effects (1), lymphocytic proliferative effects (16), and cytotoxicity against tumor cell lines (11). Studies related to the anti-inflammatory properties of chiisanoside demonstrated antioxidative mechanisms (14), and inhibition of pro-inflammatory mediators, e.g., inducible isoforms of nitric oxide synthase and cyclooxygenase-2 (17).

Recently, there has been growing concern regarding potential adverse reactions of traditional Eastern medicines, which are popular not only in Asia but also in Western countries (18). The available reliable toxicological information regarding ADA is insufficient to alleviate this concern, although ADA has long been used as a traditional medicine and several reports have confirmed its medical effects. A few studies have reported on the safety and risk of ADA to date. One clinical case report showed that intravascular (i.v.) injection of Acanthopanax spp. in patients with cerebrovascular disease caused adverse reactions, e.g., rash, papules, nausea, vomiting, and diarrhea (19). An in vitro study revealed that ADA extracts were not mutagenic and contained anti-mutagenic activities (20).

However, no full-scale toxicological report focusing on ADA extract has been published to date, despite these considerations and its wide clinical use. In a recent study, the safety of ADA was evaluated by examining its subchronic toxicity in rats following a 90-day repeated oral dosing schedule.

\section{MATERIALS AND METHODS}

Test material. ADA dry powder was supplied from the Ministry of Food and Drug Safety (MFDS) of Korea. A voucher specimen (CNU12104) of ADA was previously deposited in the herbarium at College of Pharmacy, Chungnam National University, Republic of Korea (21). The bark of the stem and root of ADA were used for preparing a dry powder. The powder was extracted from an Oriental herb decoction and frozen dry, preserved at $4 \sim 7^{\circ} \mathrm{C}$, and reconstituted in water for injection (Choongwae Pharma Co., Seoul, Korea) to the final test concentrations applied in this study (described below). Water for injection served as the vehicle control.

Determination of ADA contents was performed using high-performance liquid chromatography (Agilent 1100 Series: Agilent Technologies Ltd., Santa Clara, CA, USA) with a YMC ODS H-80 column $(4.6 \mathrm{~mm} \times 150 \mathrm{~mm}$; particle size $5 \mu \mathrm{m}$ ) and, gradient elution in a mixture of acetonitrile and $\mathrm{H}_{2} \mathrm{O}$ (14:86), a flow rate of $1 \mathrm{~mL} / \mathrm{min}$, and ultraviolet detection (wavelength: $210 \mathrm{~nm}$ ). Acanthoside D was used as the standard reference to identify and quantify the major component of ADA. The peak retention time for the test compound $(11.033 \mathrm{~min})$ was nearly identical to that of the standard reference $(11.046 \mathrm{~min})$.

Animals and experimental design. Five-week-old specific pathogen free male and female Fisher 344 rats were purchased from Harlan (Indianapolis, IN, USA) and acclimated for 1 week. The rat body weight was $112.3 \sim 165.6 \mathrm{~g}$ for males and $81.2 \sim 115.8 \mathrm{~g}$ for females. The rats were housed individually in stainless steel wire-bottom cages and supplied with commercial rodent diet $\left(\right.$ LabDiet $^{\mathbb{Q}}$, St. Louis, MO, USA) and filtered tap water ad libitum. Environmental conditions were controlled to provide a temperature of $21 \sim 24^{\circ} \mathrm{C}$, relative humidity of $46 \sim 65 \%, 12: 12$-hr light : dark cycle, and fresh air ventilation (10 15 times per hr). The study was conducted at Biotoxtech Co., Ltd., Korea following Good Laboratory Practice guidelines, as inspected by the MFDS. All procedures were performed following guidelines of the "Descriptions of NTP Study Types, Toxicology/ Carcinogenicity, 13-Week Toxicity Study" (National Toxicology Program [NTP], U.S Department of Health and Human Services, web page last updated on June 27, 2014, at http:/ntp.niehs.nih.gov/testing/types/cartox/protocols/13week/ index.html/) and "Standards for Toxicity Studies of Drugs, notification No.2000-63" from the MFDS (adopted December 11, 2000, last updated on January 29, 2014, at http:// www.mfds.go.kr/index.do? $\mathrm{mid}=686 \&$ page $\mathrm{No}=9 \& \mathrm{seq}=$ $7679 \& \mathrm{cmd}=\mathrm{v} /$ ).

The rats were assigned to 6 groups ( 10 rats per sex per group) treated as follows: group 1 (vehicle, $5 \mathrm{~mL}$ of water for injection $\left.[\mathrm{WFI}] \cdot \mathrm{kg}^{-1} \cdot \mathrm{day}^{-1}\right)$, group $2(1,000 \mathrm{mg} \mathrm{ADA} /$ $\left.5 \mathrm{~mL} \mathrm{WFI} \cdot \mathrm{kg}^{-1} \cdot \mathrm{day}^{-1}\right)$, group $3(1,500 \mathrm{mg} \mathrm{ADA} / 5 \mathrm{~mL}$ WFI $\cdot \mathrm{kg}^{-1} \cdot$ day $\left.^{-1}\right)$, group $4(2,000 \mathrm{mg} \mathrm{ADA} / 5 \mathrm{~mL}$ WFI . $\mathrm{kg}^{-1} \cdot$ day $\left.^{-1}\right)$, group $5\left(2,500 \mathrm{mg} \mathrm{ADA} / 5 \mathrm{~mL} \mathrm{WFI} \cdot \mathrm{kg}^{-1}\right.$. day $\left.^{-1}\right)$, and group $6\left(3,000 \mathrm{mg} \mathrm{ADA} / 5 \mathrm{~mL} \mathrm{WFI} \cdot \mathrm{kg}^{-1} \cdot\right.$ day $\left.^{-1}\right)$. The highest dose was selected as $3,000 \mathrm{mg} / \mathrm{kg} /$ day on the basis of a 2-week repeat dose toxicity preliminary study (data not shown), in which no adverse effects were observed.

Animals were orally dosed 5 times per week for 13 consecutive weeks using a sonde attached to a disposable syringe.

Animal observation. All animals were weighed individually immediately prior to dosing on day 1 and once a week thereafter. Body weight data from the day of necropsy were not included in the evaluation of body weight because these data reflected the fasted body weight of the animals. All animals were observed daily at 6-hr intervals for mortality, general condition, and clinical signs before the test and throughout the dosing period. Clinical observations, including motor activity, appearance, and central and autonomic functions, were performed once a week. Daily food consumption was measured before the initiation of 
dosing and once a week thereafter. Food consumption was calculated by subtracting the amount of leftover feed from the total feed provided.

Urinalysis. Urinalysis was performed for 5 rats in each group on week 13 of administration. Fresh urine (sampled within approximately $3 \mathrm{hr}$ of urine excretion) was collected to determine $\mathrm{pH}$, protein, glucose, ketone body, bilirubin, and occult blood using a urine analyzer (Miditron ${ }^{\circledR}$ Junior II, Roche Diagnostics, Mannheim, Germany) or test kits (Combur 10 Test $^{\mathbb{B}} \mathrm{M}$ stick; Roche Diagnostics). Urine was also visually observed for color and turbidity and the sediment was examined microscopically (Olympus BX50, Olympus Optical Co., Tokyo, Japan). In addition, 24-hr urine (after excretion) samples were examined for urine volume, specific gravity, sodium, and potassium using a measuring cylinder, a specific gravimeter (Vet360, Reichert, Depew, NY, USA), or an automatic analyzer (AVL9181, Roche Diagnostics, Mannheim, Germany).

Hematology and serum chemistry. On day 90, animals were fasted overnight and then anesthetized the following day with ether prior to being euthanized by exsanguination from the abdominal aorta. Blood was collected from the rats for determination of routine hematological and serum biochemistry analysis.

Hematology measurements (Cell-dyn 3700, Abbott; Holliston, MA, USA or ACL 7000, Instrumentation Laboratory, Bedford, MA, USA) included the following: total erythrocyte count (RBC), hemoglobin concentration (HGB), hematocrit (HCT), mean cell volume (MCV), mean cell hemoglobin $(\mathrm{MCH})$, mean cell hemoglobin concentration (MCHC), platelet count (PLT), total leukocyte count (WBC), WBC differential count (neutrophil, lymphocyte, monocyte, eosinophil, and basophil ratio), reticulocyte count (Reti), prothrombin time (PT), and activated partial thromboplastin time (APTT).

Serum biochemistry parameters (Integra 400, Roche Diagnostics) included: alanine aminotransferase (ALT), aspartate aminotransferase (AST), alkaline phosphatase (ALP), lactate dehydrogenase (LDH), blood urea nitrogen (BUN), creatine kinase (CK), creatinine (Crea), total bilirubin (T-Bili), total protein (TP), albumin (Alb), albumin/ globulin $(\mathrm{A} / \mathrm{G})$ ratio, total cholesterol (T-Chol), triglyceride (TG), glucose (Glu), and calcium (Ca).

\section{Necropsy, organ weight, and histopathological evalua-}

tion. All rats underwent complete necropsy following blood sample collection, which included examination of the external surfaces of the body, all orifices, and the cranial, thoracic, and abdominal cavities and their contents. The following organs were trimmed and weighed: the heart, liver, thymus, right kidney, right testis, and lungs. Organ-to-body weight ratios were calculated for each of these organs. The following organ/tissues were preserved in $10 \%$ neutral buffered formalin: the liver, lungs, trachea, heart, kidneys, adrenals, spleen, thymus, esophagus, stomach, duodenum, jejunum, ileum, cecum, colon, pancreas, brain, pituitary, testes, right epididymis, prostate, ovaries, uterus, vagina, seminal vesicle, clitoral glands, preputial glands, rectum, aorta, urinary bladder, eyes and harderian gland, mandibular lymph nodes, mesenteric lymph nodes, mammary gland, skin, skeletal muscle, sciatic nerve, nasal turbinates, larynx, pharynx, thyroids, parathyroids, salivary glands, spinal cord, zymbal glands, and femur. The eyes/optic nerve and testes were preserved in Davidson's and Bouin solution, respectively. All of the preserved tissues from rats receiving 0 , 2,500, and 3,000 mg/kg ADA were paraffin-embedded, sectioned, stained with hematoxylin and eosin, and examined microscopically.

Vaginal cytology. Five female rats in each group were evaluated for vaginal cytology on weeks 11 and 12 of the study. Vaginal smears were collected every morning for 10 days, stained with Diff-Quick solution, and observed microscopically. The estrous cycle was determined by the features of each cell type in the vaginal smear and characterized as proestrus, estrus, metestrus, or diestrus.

Sperm motility and deformity test. Five male rats in each group were evaluated at the time of necropsy. Sperm was collected from the left cauda of the epididymis. After 10 -min of incubation in modified Tyrode's medium at $37^{\circ} \mathrm{C}$, the sperm were counted using a sperm counting chamber under a light microscope. Sperm motility was calculated as follows: sperm motility $=($ moving sperm $/ 100$ sperm $) \times 100$. To determine the sperm deformity rate, the incubated sperm fluid was smeared, stained with Diff-Quick, and evaluated microscopically. Two hundred sperm from each rat were examined for shape and deformity, and the sperm deformity rate (\%) was calculated as follows: sperm deformity rate $(\%)=($ number of sperm deformed/total number of sperm) $\times 100$.

Statistical analysis. A statistical analysis was performed for the cumulative body-weight-gain, food consumption, urine volume, hematology and serum biochemistry parameters, sperm motility, sperm deformity, vaginal cytology, organ weights, and organ/body weight. For the control and ADA-treated groups, homogeneity of the variance of numerical data was determined by Levene's test. For homogenous data, groups were compared by one-way analysis of variance (ANOVA); for heterogeneous data, groups were compared by the non-parametric Kruskal-Wallis test. If statistical significance was observed $(P<0.05)$, Dunnett's test (for ANOVA) or the Steel test (for Kruskal-Wallis) was used for multiple comparisons of the control group with each dosage group. 


\section{RESULTS}

Clinical signs, body weight and food consumption. One male that received $1,000 \mathrm{mg} / \mathrm{kg}$ ADA died on day 81 . Salivation was observed intermittently during the dosing period and only directly after dosing in both sexes receiving 2,500 and $3,000 \mathrm{mg} / \mathrm{kg}$ of ADA. Cumulative bodyweight-gain were significantly decreased in females receiving 1,500 and $2,000 \mathrm{mg} / \mathrm{kg}$ ADA at week 2 when compared with control values $(P<0.05)$ (Fig. 1). Food consumption was significantly decreased in females receiving $3,000 \mathrm{mg} /$ $\mathrm{kg} \mathrm{ADA}$ at week 12 when compared with values of the con- trol group $(P<0.05)$ (Fig. 2).

Urinalysis. Proteins $(150 \mathrm{mg} / \mathrm{dL})$ and ketone body (15 $\mathrm{mg} / \mathrm{dL}$ ) levels above control values were detected in one male receiving $3,000 \mathrm{mg} / \mathrm{kg}$ ADA.

Hematology. Statistically significant differences were not observed for any hematology parameter (data not shown).

Serum chemistry. The T-Chol level was significantly decreased in males receiving 1,500 and $2,000 \mathrm{mg} / \mathrm{kg}$ ADA $(P<0.01$ and 0.05 , respectively) compared with the con-

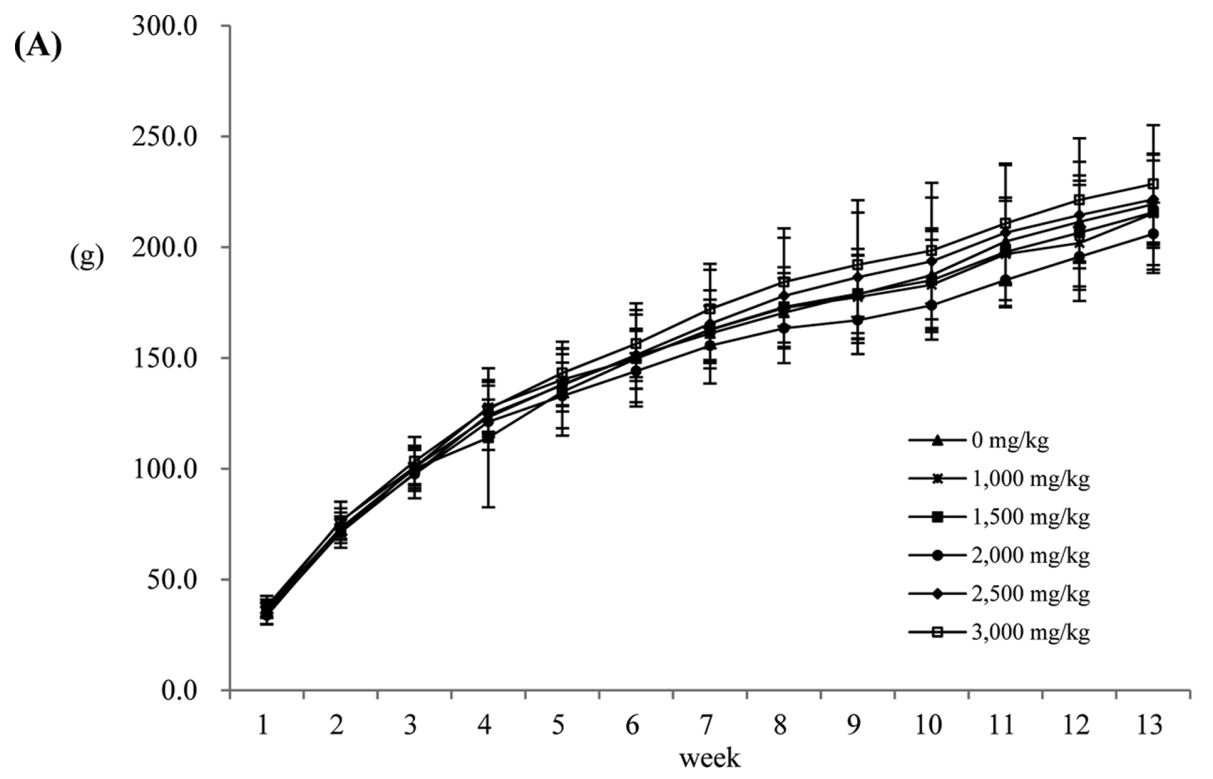

(B)

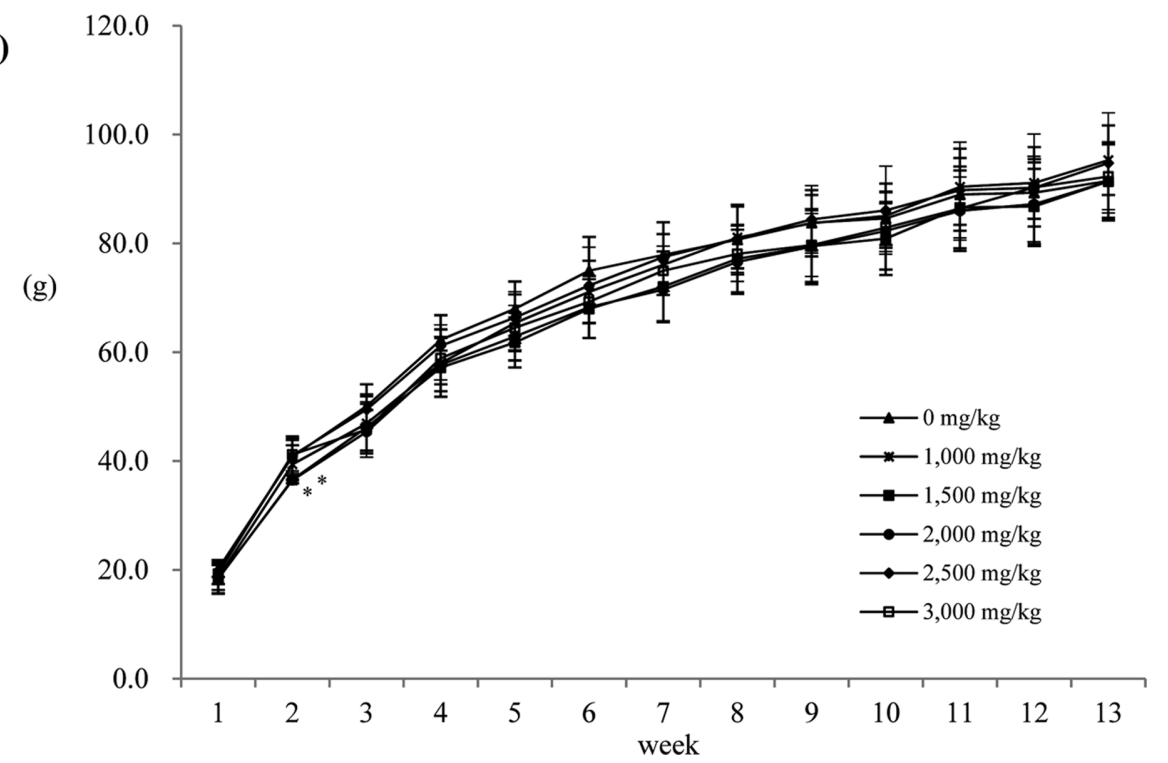

Fig. 1. Cumulative body-weight-gain in rats treated orally with $A D A$ for thirteen weeks. No change was observed in male (A) during the dosing period. Significant decrease was observed in females (B) receiving 1,500 and $2,000 \mathrm{mg} / \mathrm{kg} \mathrm{ADA}$ at week 2 . *Significant difference from the control group at $p<0.05$. 
trol group (Table 1).

Organ weight. The absolute and relative liver weight significantly increased in females receiving 2,000, 2,500 and $3,000 \mathrm{mg} / \mathrm{kg} \mathrm{ADA}$, compared with the control group (absolute: $P<0.05, P<0.01$, and $P<0.01$, respectively; relative: $P<0.001$ ) (Table 2,3 ).

Statistically significant differences were also observed in the absolute and relative weight of the right kidney in rats of both sexes treated with ADA at 2,000, 2,500, and/or $3,000 \mathrm{mg} / \mathrm{kg}$ and in the heart of females treated with ADA at $2,500 \mathrm{mg} / \mathrm{kg}$ compared with their corresponding controls
(Table 2, 3).

Necropsy and histopathological evaluations. At necropsy, pulmonary congestion and the presence of the test substance in the thoracic cavity were observed in the dead rat. In histopathology, diffuse congestion was observed in the lung.

All macroscopic findings for the eye, liver, and ovaries were considered to be incidental and of no toxicological significance (data not shown). Microscopic examination of the liver, kidneys, heart, and salivary glands did not reveal any ADA-related changes that could be attributed to
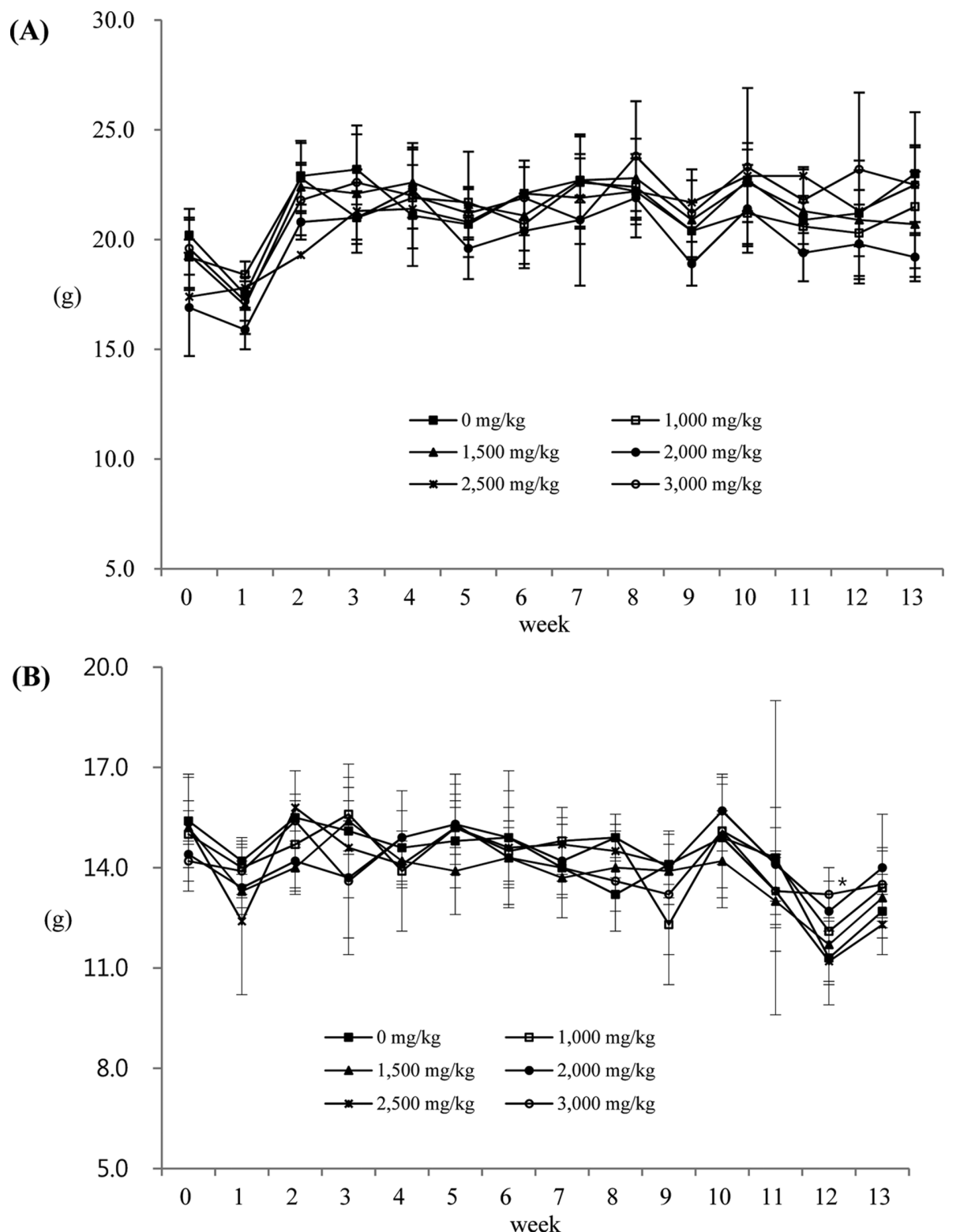

Fig. 2. Food consumption in rats treated orally with $A D A$ for thirteen weeks. No change was observed in male (A) during the dosing period. Significant decrease was observed in females (B) receiving $3,000 \mathrm{mg} / \mathrm{kg} \mathrm{ADA}$ at week 12 . *Significant difference from the control group at $p<0.05$. 
Table 1. Serum chemistry in rats treated orally with ADA for thirteen weeks

\begin{tabular}{|c|c|c|c|c|c|c|}
\hline \multirow{2}{*}{$\begin{array}{c}\text { Parameter } \\
\text { (units of measure) }\end{array}$} & \multicolumn{6}{|c|}{ Dose $(\mathrm{mg} / \mathrm{kg})$} \\
\hline & 0 & 1,000 & 1,500 & 2,000 & 2,500 & 3,000 \\
\hline \multicolumn{7}{|l|}{ Males } \\
\hline Number of animals & 10 & $9^{\dagger}$ & 10 & 10 & 10 & 10 \\
\hline $\operatorname{ALT}(\mathrm{U} / \mathrm{L})$ & $50.7 \pm 10.4^{\mathrm{a}}$ & $46.0 \pm 5.4$ & $47.8 \pm 12.2$ & $39.7 \pm 3.9$ & $45.2 \pm 9.4$ & $43.8 \pm 5.9$ \\
\hline AST (U/L) & $108.0 \pm 21.1$ & $102.4 \pm 16.2$ & $107.5 \pm 24.5$ & $92.4 \pm 8.2$ & $102.5 \pm 22.6$ & $95.2 \pm 12.7$ \\
\hline ALP (U/L) & $123.9 \pm 11.6$ & $120.8 \pm 7.8$ & $116.8 \pm 6.6$ & $124.1 \pm 6.0$ & $118.9 \pm 9.3$ & $115.9 \pm 3.5$ \\
\hline LDH (U/L) & $1334.1 \pm 972.6$ & $1066.9 \pm 745.6$ & $915.2 \pm 570.0$ & $984.4 \pm 356.1$ & $1011.5 \pm 360.1$ & $883.9 \pm 372.6$ \\
\hline $\mathrm{CK}(\mathrm{U} / \mathrm{L})$ & $381.5 \pm 272.1$ & $296.1 \pm 190.1$ & $264.2 \pm 158.6$ & $287.8 \pm 93.8$ & $294.8 \pm 84.5$ & $264.9 \pm 96.8$ \\
\hline Glucose (mg/dL) & $135.0 \pm 21.7$ & $137.2 \pm 16.3$ & $137.6 \pm 13.1$ & $134.5 \pm 12.2$ & $128.2 \pm 10.2$ & $132.6 \pm 9.9$ \\
\hline BUN (mg/dL) & $15.7 \pm 1.4$ & $16.4 \pm 0.9$ & $15.4 \pm 1.5$ & $15.3 \pm 2.1$ & $16.1 \pm 1.7$ & $15.4 \pm 0.8$ \\
\hline Creatinine $(\mathrm{mg} / \mathrm{dL})$ & $0.6 \pm 0.0$ & $0.6 \pm 0.0$ & $0.6 \pm 0.0$ & $0.5 \pm 0.0$ & $0.5 \pm 0.0$ & $0.5 \pm 0.0$ \\
\hline Total bilirubin (mg/dL) & $0.1 \pm 0.0$ & $0.1 \pm 0.0$ & $0.1 \pm 0.0$ & $0.1 \pm 0.0$ & $0.1 \pm 0.0$ & $0.1 \pm 0.0$ \\
\hline Total cholesterol (mg/dL) & $67.0 \pm 7.6$ & $61.2 \pm 7.8$ & $54.8 \pm 8.8^{* * *}$ & $56.0 \pm 6.4^{*}$ & $60.2 \pm 7.3$ & $62.7 \pm 11.4$ \\
\hline Triglyceride (mg/dL) & $119.1 \pm 48.1$ & $114.9 \pm 49.1$ & $91.7 \pm 23.8$ & $89.7 \pm 27.9$ & $94.2 \pm 47.1$ & $87.1 \pm 33.5$ \\
\hline Total protein $(\mathrm{g} / \mathrm{dL})$ & $6.8 \pm 0.1$ & $6.8 \pm 0.2$ & $6.7 \pm 0.2$ & $6.7 \pm 0.2$ & $6.7 \pm 0.2$ & $6.7 \pm 0.2$ \\
\hline Albumin $(\mathrm{g} / \mathrm{dL})$ & $3.8 \pm 0.1$ & $3.8 \pm 0.1$ & $3.8 \pm 0.1$ & $3.8 \pm 0.1$ & $3.7 \pm 0.1$ & $3.8 \pm 0.1$ \\
\hline $\mathrm{A} / \mathrm{G}$ ratio & $1.3 \pm 0.0$ & $1.3 \pm 0.1$ & $1.3 \pm 0.1$ & $1.3 \pm 0.1$ & $1.3 \pm 0.0$ & $1.3 \pm 0.0$ \\
\hline $\mathrm{Ca}(\mathrm{mmol} / \mathrm{dL})$ & $2.7 \pm 0.1$ & $2.7 \pm 0.1$ & $2.7 \pm 0.1$ & $2.7 \pm 0.1$ & $2.7 \pm 0.0$ & $2.7 \pm 0.1$ \\
\hline \multicolumn{7}{|l|}{ Females } \\
\hline Number of animals & 10 & 10 & 10 & 10 & 10 & 10 \\
\hline $\operatorname{ALT}(\mathrm{U} / \mathrm{L})$ & $40.5 \pm 3.3$ & $38.4 \pm 2.7$ & $42.2 \pm 8.9$ & $41.2 \pm 7.8$ & $38.5 \pm 5.3$ & $41.8 \pm 8.6$ \\
\hline AST (U/L) & $96.7 \pm 7.7$ & $94.9 \pm 9.0$ & $93.7 \pm 11.7$ & $95.4 \pm 10.4$ & $91.7 \pm 10.5$ & $98.7 \pm 19.3$ \\
\hline ALP (U/L) & $105.4 \pm 12.2$ & $98.3 \pm 7.9$ & $100.7 \pm 10.7$ & $100.4 \pm 13.4$ & $98.2 \pm 7.5$ & $96.0 \pm 8.4$ \\
\hline LDH (U/L) & $648.2 \pm 257.3$ & $669.0 \pm 297.2$ & $531.0 \pm 188.3$ & $742.1 \pm 189.4$ & $624.2 \pm 255.1$ & $670.0 \pm 217.6$ \\
\hline $\mathrm{CK}(\mathrm{U} / \mathrm{L})$ & $207.8 \pm 75.6$ & $215.1 \pm 86.2$ & $173.4 \pm 49.9$ & $247.8 \pm 65.3$ & $198.9 \pm 67.4$ & $210.3 \pm 63.9$ \\
\hline Glucose (mg/dL) & $112.8 \pm 6.1$ & $115.0 \pm 10.0$ & $111.5 \pm 8.5$ & $112.5 \pm 7.9$ & $109.6 \pm 9.6$ & $115.5 \pm 7.1$ \\
\hline BUN (mg/dL) & $17.1 \pm 1.9$ & $17.1 \pm 1.0$ & $17.1 \pm 1.2$ & $18.0 \pm 1.9$ & $16.9 \pm 1.9$ & $17.6 \pm 3.4$ \\
\hline Creatinine $(\mathrm{mg} / \mathrm{dL})$ & $0.5 \pm 0.0$ & $0.5 \pm 0.0$ & $0.5 \pm 0.0$ & $0.6 \pm 0.0$ & $0.5 \pm 0.0$ & $0.6 \pm 0.0$ \\
\hline Total bilirubin (mg/dL) & $0.1 \pm 0.0$ & $0.1 \pm 0.0$ & $0.1 \pm 0.0$ & $0.1 \pm 0.1$ & $0.1 \pm 0.0$ & $0.1 \pm 0.0$ \\
\hline Total cholesterol $(\mathrm{mg} / \mathrm{dL})$ & $74.6 \pm 4.5$ & $75.7 \pm 5.5$ & $79.4 \pm 7.5$ & $70.7 \pm 7.7$ & $69.6 \pm 7.1$ & $73.8 \pm 7.4$ \\
\hline Triglyceride (mg/dL) & $36.7 \pm 8.5$ & $33.4 \pm 7.1$ & $34.9 \pm 7.9$ & $33.3 \pm 7.7$ & $30.4 \pm 7.8$ & $33.1 \pm 9.0$ \\
\hline Total protein $(\mathrm{g} / \mathrm{dL})$ & $6.5 \pm 0.2$ & $6.6 \pm 0.2$ & $6.6 \pm 0.1$ & $6.6 \pm 0.2$ & $6.5 \pm 0.2$ & $6.7 \pm 0.2$ \\
\hline Albumin $(\mathrm{g} / \mathrm{dL})$ & $3.7 \pm 0.1$ & $3.7 \pm 0.1$ & $3.7 \pm 0.1$ & $3.7 \pm 0.1$ & $3.7 \pm 0.1$ & $3.7 \pm 0.1$ \\
\hline $\mathrm{A} / \mathrm{G}$ ratio & $1.3 \pm 0.1$ & $1.2 \pm 0.1$ & $1.3 \pm 0.1$ & $1.3 \pm 0.1$ & $1.3 \pm 0.0$ & $1.3 \pm 0.1$ \\
\hline $\mathrm{Ca}(\mathrm{mmol} / \mathrm{dL})$ & $2.7 \pm 0.1$ & $2.7 \pm 0.1$ & $2.8 \pm 0.1$ & $2.7 \pm 0.1$ & $2.7 \pm 0.1$ & $2.7 \pm 0.0$ \\
\hline
\end{tabular}

${ }_{* * * *}^{*}$ Significant difference from the control group at $P<0.05$ and 0.01 , respectively.

One male was excluded because of death during dosing period.

aalues indicate mean \pm SD.

increased organ weight or salivation. All other microscopic findings for the adrenals, eyes, harderian glands, thymus, lungs, pancreas, prostate, spleen, and ovaries were consistent with the normal background lesions in Fisher 344 rats of the same age group as the rats included in the study and were therefore considered to be spontaneous and incidental in nature (data not shown).

Vaginal cytology. No statistically significant changes in estrous cycle were observed in any of the ADA groups compared to the control group.

Sperm motility and deformity test. No statistically significant changes were noted in sperm motility or defor- mity in any of the ADA groups, compared to the control group.

\section{DISCUSSION}

We evaluated the potential toxicity of ADA in rats to determine its safe use in clinical practice as a traditional medicine.

One male from the low-dose ADA group $(1,000 \mathrm{mg} / \mathrm{kg})$ was found dead on day 81 before the end of the study. The cause of death was suspected to be related to gavage error based on the presence of the test substance in the thoracic cavity at necropsy. No deaths were observed in the higher dose groups. 
Table 2. Absolute organ weights in rats treated orally with ADA for thirteen weeks

\begin{tabular}{|c|c|c|c|c|c|c|}
\hline \multirow{2}{*}{ Organs (g) } & \multicolumn{6}{|c|}{ Dose (mg/kg) } \\
\hline & 0 & 1,000 & 1,500 & 2,000 & 2,500 & 3,000 \\
\hline \multicolumn{7}{|l|}{ Males } \\
\hline Number of animals & 10 & $9^{\dagger}$ & 10 & 10 & 10 & 10 \\
\hline Liver & $9.53 \pm 0.88^{\mathrm{a}}$ & $9.79 \pm 1.02$ & $9.72 \pm 0.83$ & $9.04 \pm 0.54$ & $9.94 \pm 0.68$ & $10.25 \pm 1.08$ \\
\hline Kidney (right) & $1.06 \pm 0.08$ & $1.09 \pm 0.13$ & $1.08 \pm 0.10$ & $1.04 \pm 0.07$ & $1.12 \pm 0.09$ & $1.13 \pm 0.11$ \\
\hline Heart & $0.98 \pm 0.08$ & $0.97 \pm 0.09$ & $0.99 \pm 0.06$ & $0.93 \pm 0.07$ & $1.00 \pm 0.05$ & $1.00 \pm 0.10$ \\
\hline Lung & $1.32 \pm 0.07$ & $1.36 \pm 0.11$ & $1.32 \pm 0.11$ & $1.26 \pm 0.11$ & $1.37 \pm 0.12$ & $1.35 \pm 0.13$ \\
\hline Thymus & $0.254 \pm 0.038$ & $0.245 \pm 0.045$ & $0.254 \pm 0.030$ & $0.242 \pm 0.031$ & $0.244 \pm 0.009$ & $0.247 \pm 0.034$ \\
\hline Testis (right) & $1.482 \pm 0.063$ & $1.436 \pm 0.108$ & $1.447 \pm 0.080$ & $1.421 \pm 0.043$ & $1.489 \pm 0.055$ & $1.449 \pm 0.164$ \\
\hline \multicolumn{7}{|l|}{ Females } \\
\hline Number of animals & 10 & 10 & 10 & 10 & 10 & 10 \\
\hline Liver & $4.52 \pm 0.18$ & $4.86 \pm 0.26$ & $4.66 \pm 0.22$ & $4.88 \pm 0.27^{*}$ & $4.98 \pm 0.42^{* *}$ & $5.02 \pm 0.38^{* * *}$ \\
\hline Kidney (right) & $0.61 \pm 0.05$ & $0.64 \pm 0.03$ & $0.62 \pm 0.03$ & $0.64 \pm 0.03$ & $0.66 \pm 0.05^{*}$ & $0.66 \pm 0.03^{*}$ \\
\hline Heart & $0.62 \pm 0.04$ & $0.66 \pm 0.04$ & $0.61 \pm 0.04$ & $0.64 \pm 0.03$ & $0.67 \pm 0.04^{*}$ & $0.64 \pm 0.05$ \\
\hline Lung & $0.97 \pm 0.06$ & $0.99 \pm 0.05$ & $0.91 \pm 0.07$ & $0.98 \pm 0.09$ & $1.00 \pm 0.07$ & $0.96 \pm 0.03$ \\
\hline Thymus & $0.233 \pm 0.016$ & $0.215 \pm 0.016$ & $0.215 \pm 0.019$ & $0.212 \pm 0.025$ & $0.227 \pm 0.019$ & $0.211 \pm 0.023$ \\
\hline
\end{tabular}

**** Significant difference from the control group at $P<0.05$ and 0.01 , respectively.

One male was excluded because of death during dosing period.

aValues indicate mean \pm SD.

Table 3. Relative organ weights in rats treated orally with ADA for thirteen weeks

\begin{tabular}{|c|c|c|c|c|c|c|}
\hline \multirow{2}{*}{$\begin{array}{l}\text { Organs } \\
\text { (g/100 g body weight) }\end{array}$} & \multicolumn{6}{|c|}{ Dose (mg/kg) } \\
\hline & 0 & 1,000 & 1,500 & 2,000 & 2,500 & 3,000 \\
\hline \multicolumn{7}{|l|}{ Males } \\
\hline Number of animals & 10 & $9^{\dagger}$ & 10 & 10 & 10 & 10 \\
\hline Liver & $2.82 \pm 0.17^{\mathrm{a}}$ & $2.94 \pm 0.08$ & $2.90 \pm 0.10$ & $2.90 \pm 0.14$ & $2.93 \pm 0.17$ & $2.96 \pm 0.12$ \\
\hline Kidney (right) & $0.31 \pm 0.01$ & $0.33 \pm 0.01$ & $0.32 \pm 0.01$ & $0.33 \pm 0.01^{* *}$ & $0.33 \pm 0.02^{*}$ & $0.33 \pm 0.02$ \\
\hline Heart & $0.29 \pm 0.02$ & $0.29 \pm 0.01$ & $0.30 \pm 0.01$ & $0.30 \pm 0.01$ & $0.29 \pm 0.02$ & $0.29 \pm 0.01$ \\
\hline Lung & $0.39 \pm 0.02$ & $0.41 \pm 0.02$ & $0.39 \pm 0.02$ & $0.41 \pm 0.03$ & $0.40 \pm 0.02$ & $0.39 \pm 0.02$ \\
\hline Thymus & $0.076 \pm 0.012$ & $0.073 \pm 0.012$ & $0.076 \pm 0.009$ & $0.078 \pm 0.009$ & $0.072 \pm 0.004$ & $0.072 \pm 0.013$ \\
\hline Testis (right) & $0.440 \pm 0.010$ & $0.432 \pm 0.012$ & $0.434 \pm 0.020$ & $0.457 \pm 0.018$ & $0.440 \pm 0.029$ & $0.418 \pm 0.032$ \\
\hline \multicolumn{7}{|l|}{ Females } \\
\hline Number of animals & 10 & 10 & 10 & 10 & 10 & 10 \\
\hline Liver & $2.44 \pm 0.13$ & $2.58 \pm 0.09$ & $2.54 \pm 0.09$ & $2.66 \pm 0.11^{* * * *}$ & $2.67 \pm 0.12^{* * * *}$ & $2.73 \pm 0.16^{* * *}$ \\
\hline Kidney (right) & $0.33 \pm 0.03$ & $0.34 \pm 0.02$ & $0.34 \pm 0.02$ & $0.35 \pm 0.02$ & $0.35 \pm 0.03$ & $0.36 \pm 0.01^{*}$ \\
\hline Heart & $0.33 \pm 0.02$ & $0.35 \pm 0.02$ & $0.34 \pm 0.03$ & $0.35 \pm 0.02$ & $0.36 \pm 0.02$ & $0.35 \pm 0.02$ \\
\hline Lung & $0.52 \pm 0.04$ & $0.53 \pm 0.30$ & $0.50 \pm 0.04$ & $0.53 \pm 0.05$ & $0.53 \pm 0.04$ & $0.52 \pm 0.02$ \\
\hline Thymus & $0.126 \pm 0.010$ & $0.114 \pm 0.006$ & $0.118 \pm 0.008$ & $0.115 \pm 0.014$ & $0.121 \pm 0.009$ & $0.115 \pm 0.012$ \\
\hline
\end{tabular}

${ }_{*, * * * * * * *}$ Significant difference from the control group at $P<0.05,0.01$, and 0.001 , respectively.

One male was excluded because of death during dosing period.

aalues indicate mean \pm SD.

Salivation was intermittently observed in both sexes receiving 2,500 and $3,000 \mathrm{mg} / \mathrm{kg}$ of ADA directly after dosing. This finding was considered to be related to ADA treatment. However, it was not considered to be an adverse change because it was intermittent, transient and not accompanied by any changes such as other pathological signs, histopathological alterations, or abnormal behavior. As ADA has a bitter taste (9) and salivation can be evoked by bitter taste stimulation (22), the salivation observed in this study may be related to the bitter taste of ADA. Saliva can also be secreted as a response to cholinergic and noradrenergic impulses of the autonomic nervous system (23). However, it is not clear whether ADA has any cholinergic or adrenergic effects. In general, cholinergic- and adrenergic- drugs show other clinical manifestations such as diarrhea, urination, emesis, lacrimation, and appetite suppression (24), which were not observed in this study.

The cumulative body-weight-gain in females receiving 
1,500 and $2,000 \mathrm{mg} / \mathrm{kg} \mathrm{ADA}$ and food consumption in females receiving $3,000 \mathrm{mg} / \mathrm{kg}$ ADA decreased on weeks 2 and 12 , respectively. These effects were not considered to be ADA-related on the basis of their small magnitude, temporary change, and lack of dose-dependent response.

In urinalysis, protein $(3+)$ and ketone body $(2+)$ levels were above control values in one male receiving $3,000 \mathrm{mg} /$ $\mathrm{kg}$ ADA. However, proteinuria and ketonuria in this rat were not considered to be ADA-related because the occurrence was infrequent and there was no evidence of renal injury or metabolic alteration of fat including failure of body-weight-gain and food consumption increase.

Biochemical examination of the serum revealed a significantly decreased T-Chol level in males that received 1,500 and $2,000 \mathrm{mg} / \mathrm{kg}$ ADA. However, this change was also not considered to be ADA-related based on the lack of a dosedependent response, the small magnitude of the effect, and the isolated nature of the change.

In this study, the liver weight increased dose-dependently in females receiving 2,000, 2,500, and 3,000 mg/kg ADA. These increases in liver weight were considered to be ADA-related based on the dose-dependent response. However, this was not considered to be an adverse reaction because the change was minor and isolated without associated hepatic morphological or functional alterations. No elevation of ALT or AST or hepatocytic injury was observed in this study. The liver weight change was within $12 \%(8.0 \sim$ $11.9 \%$ ) compared with concurrent control female rats. An increase of liver weight, at least up to $20 \%$, in the absence of other liver pathologies except for hypertrophy and hyperplasia is often regarded as a non-adverse effect in rodents (25). The lack of biologically significant change in a marker indicating hepatobiliary damage or liver dysfunction further supports that increased liver weight is a non-adverse effect (26-28).

Statistically significant differences between the ADA and control groups were also observed in the weights of the kidney and heart. However, these changes were not considered to be ADA-related effects because they were very small, i.e., within only one standard deviation from the mean background levels (29); furthermore, they lacked dose dependence and were not associated with any morphological alterations.

All macroscopic and microscopic changes observed were not considered to be ADA-related because they were incidental, spontaneous in nature, or showed similar frequency among control and test groups in both sexes.

Taken together, our results indicate that ADA does not induce any adverse effects in rats receiving a dose of 3,000 $\mathrm{mg} / \mathrm{kg}$ or less for 13 weeks under the conditions employed in this study. The no-observed-adverse-effect-level was determined to be at least $3,000 \mathrm{mg} / \mathrm{kg}$ in both sexes of rats. These results could contribute to further evaluations of the toxicity of ADA for humans and should prove useful for more detailed investigations of its pharmacological effects.

\section{CONFLICT OF INTEREST}

The authors declare that there are no conflict of interest.

\section{ACKNOWLEDGMENTS}

This work was supported by the Korea National Toxicology Program (04122MFDS229) from the Ministry of Food and Drug Safety. We are grateful to all of the researchers who contributed to this study.

\section{REFERENCES}

1. Yook, C.S., Rho, Y.S., Seo, S.H., Leem, J.Y. and Han, D.R. (1996) Chemical components of Acanthopanax divaricatus and anticancer effect in leaves. Yakhakhoe Chi, 40, 251-261.

2. Kim, J.-H. and Hahn, D.-R. (1981) Studies on the chemical constituents of Acanthopanax chiisanensis Nakai roots. Arch. Pharm. Res., 4, 59-62.

3. Takasugi, N., Moriguchi, T., Fuwa, T., Sanada, S., Ida, Y., Shoji, J. and Saito, H. (1985) Effect of Eleutherococcus senticosus and its components on rectal temperature, body and grip tones, motor coordination, and exploratory and spontaneous movements in acute stressed mice. Shoyakugaku Zasshi, 39, 232-237.

4. Foster, S. and Chongxi, Y. (1992) Herbal emissaries: bringing Chinese herbs to the West: a guide to gardening, herbal wisdom, and well-being, Healing arts press, Rochester, Vermont.

5. Yamazaki, T., Matsumura, T., Tsukiyama, T. and Tokiwa, T. (2006) Anti-inflammatory effects of eleutheroside E from Acanthopanax senticosus. Tissue Cult. Res. Commun. 25, 137145.

6. Lee, D., Park, J., Yoon, J., Kim, M.Y., Choi, H.Y. and Kim, H. (2012) Neuroprotective effects of Eleutherococcus senticosus bark on transient global cerebral ischemia in rats. J. Ethnopharmacol., 139, 6-11.

7. Huang, L.Z., Wei, L., Zhao, H.F., Huang, B.K., Rahman, K. and Qin, L.P. (2011) The effect of Eleutheroside E on behavioral alterations in murine sleep deprivation stress model. Eur. J. Pharmacol., 658, 150-155.

8. Nishibe, S., Kinoshita, H., Takeda, H. and Okano, G. (1990) Phenolic compounds from stem bark of Acanthopanax senticosus and their pharmacological effect in chronic swimming stressed rats. Chem. Pharm. Bull., 38, 1763-1765.

9. Hong, S.S., Hwang, J.S., Lee, S.A., Hwang, B.Y., Ha, K.W., Ze, K.R., Seung, R.S., Ro, J.S. and Lee, K.S. (2001) Isolation and quantitative analysis of acanthoside D from Acanthopanacis cortex. Saengyak Hakhoechi, 32, 316-321.

10. Kang, J.S., Linh, P.T., Cai, X.F., Kim, H.S., Lee, J.J. and Kim, Y.H. (2001) Quantitative determination of eleutheroside B and E from Acanthopanax species by high performance liquid chromatography. Arch. Pharmacol. Res., 24, 407-411.

11. Bae, E.A., Yook, C.S., Oh, O.J., Chang, S.Y., Nohara, T. and Kim, D.H. (2001) Metabolism of chiisanoside from Acanthopanax divaricatus var. albeofructus by human intestinal bacteria and its relation to some biological activities. Biol. Pharm. 
Bull., 24, 582-585.

12. Oh, O.J., Chang, S.Y., Yook, C.S., Yang, K.S., Park, S.Y. and Nohara, T. (2000) Two 3,4-seco-lupane triterpenes from leaves of Acanthopanax divaricatus var. albeofructus. Chem. Pharm. Bull., 48, 879-881.

13. Lim, E.J., Do, G.M., Shin, J.H. and Kwon, O. (2013) Protective effects of Acanthopanax divaricatus vat. albeofructus and its active compound on ischemia-reperfusion injury of rat liver. Biochem. Biophys. Res. Commun., 432, 599-605.

14. Jung, H.J., Nam, J.H., Choi, J., Lee, K.T. and Park, H.J. (2005) Antiinflammatory effects of chiisanoside and chiisanogenin obtained from the leaves of Acanthopanax chiisanensis in the carrageenan- and Freund's complete adjuvant-induced rats. J. Ethnopharmacol., 97, 359-367.

15. Lee, S., Shin, D.S., Oh, K.B. and Shin, K.H. (2003) Antibacterial compounds from the leaves of Acanthopanax senticosus. Arch. Pharmacol. Res., 26, 40-42.

16. Kim, Y.-O., Cho, D.-H., Chung, H.-J., Kim, J.-H., Chang, S.-Y., Yook, C.-S., Yang, K.-S. and Oh, O.-J. (1999) Effects of lupane-triterpenoids on mitogen-induced proliferation of lymphocytes. Yakhak Hoechi, 43, 208-213.

17. Won, J.H., Park, S.Y., Nam, S.G., Park, H.J., Choi, J.W. and Lee, K.T. (2005) Inhibition of lipopolysaccharide-induced expression of inducible nitric oxide and cyclooxygenase- 2 by chiisanoside via suppression of nuclear factor-kappaB activation in RAW 264.7 macrophage cells. Biol. Pharm. Bull., 28, 1919-1924.

18. Ko, R.J. (2004) A U.S. perspective on the adverse reactions from traditional Chinese medicines. J. Chin. Med. Assoc., 67, 109-116.

19. Xiang, B., Peng, Y. and Jiang, Y.-G. (2013) A report on the analysis of 365 cases of adverse reactions of Chinese patent drugs for heart cerebrovascular diseases. Afr. J. Pharm. Pharmacol., 7, 1267-1271.

20. Hong, C.E., Cho, M.C., Jang, H.A. and Lyu, S.Y. (2011) Mutagenicity and anti-mutagenicity of Acanthopanax divaricatus var. albeofructus. J. Toxicol. Sci., 36, 661-668.
21. Sun, Y.N., Li, W., Song, S.B., Yan, X.T., Yang, S.Y. and Kim, Y.H. (2014) NF-кB Inhibitory Activities of Phenolic and Lignan Components from the Stems of Acanthopanax divaricatus var. albeofructus. Nat. Prod. Sci., 20, 232-236.

22. Matsuo, R., Yamauchi, Y., Kobashi, M., Funahashi, M., Mitoh, Y. and Adachi, A. (2001) Role of parabrachial nucleus in submandibular salivary secretion induced by bitter taste stimulation in rats. Auton. Neurosci., 88, 61-73.

23. Cunningham, J.G. and Klein, B.G. (2007) Textbook of Veterinary Physiology (4th edition), Saunders, St. Louis, Missouri.

24. Haschek, W.M., Rousseaux, C.G., Walling, M.A., Bolon, B., Ochoa, R. and Mahler, B.W. (2013) Haschek and Rousseaux's Handbook of Toxicologic Pathology (3rd edition), Academic Press, London.

25. Karbe, E., Williams, G.M., Lewis, R.W., Kimber, I. and Foster, P.M.D. (2001) Distinguishing between adverse and nonadverse effects. J. Toxicol. Pathol., 14, 321-325.

26. Hall, A.P., Elcombe, C.R., Foster, J.R., Harada, T., Kaufmann, W., Knippel, A., Kuttler, K., Malarkey, D.E., Maronpot, R.R., Nishikawa, A., Nolte, T., Schulte, A., Strauss, V. and York, M.J. (2012) Liver hypertrophy: a review of adaptive (adverse and non-adverse) changes--conclusions from the 3rd International ESTP Expert Workshop. Toxicol. Pathol., 40, 971-994.

27. Amacher, D.E., Schomaker, S.J. and Burkhardt, J.E. (1998) The relationship among microsomal enzyme induction, liver weight and histological change in rat toxicology studies. Food Chem. Toxicol., 36, 831-839.

28. Kasai, R., Matsumoto, K., Taniyasu, S., Tanaka, O., Kim, J.-H. and Hahn, D.-R. (1986) 3,4-Seco-lupane type triterpene glycosyl esters from a Korean medicinal plant, Acanthopanax chiisanensis (Araliaceae). Chem. Pharm. Bull., 34, 3284-3289.

29. Okamura, T., Suzuki, S., Ogawa, T., Kobayashi, J., Kusuoka, O., Hatayama, K., Mochizuki, M., Hoshiya, T., Okazaki, S. and Tamura, K. (2011) Background data for general toxicology parameters in RccHan:WIST rats at 8, 10, 19 and 32 weeks of age. J. Toxicol. Pathol., 24, 195-205. 